\title{
Effect of Daily Oral Lactobacillus plantarum PS128 on Exercise Capacity Recovery after a Half-Marathon
}

\author{
Szu-Kai Fu ${ }^{1}{ }^{\mathbb{D}}$, Wei-Chin Tseng ${ }^{2}$, Kuo-Wei Tseng ${ }^{2}$, Chang-Chi Lai ${ }^{2}$, Ying-Chieh Tsai ${ }^{3} \mathbb{D}$, Hsia-Ling Tai $^{1}$ \\ and Chia-Chen $\mathrm{Hsu}^{4, *}$
}

check for

updates

Citation: Fu, S.-K.; Tseng, W.-C.; Tseng, K.-W.; Lai, C.-C.; Tsai, Y.-C.; Tai, H.-L.; Hsu, C.-C. Effect of Daily Oral Lactobacillus plantarum PS128 on Exercise Capacity Recovery after a Half-Marathon. Nutrients 2021, 13, 4023. https://doi.org/10.3390/ nu13114023

Academic Editor: Antoni Sureda

Received: 13 October 2021

Accepted: 9 November 2021

Published: 11 November 2021

Publisher's Note: MDPI stays neutral with regard to jurisdictional claims in published maps and institutional affiliations.

Copyright: (c) 2021 by the authors. Licensee MDPI, Basel, Switzerland. This article is an open access article distributed under the terms and conditions of the Creative Commons Attribution (CC BY) license (https:/ / creativecommons.org/licenses/by/ $4.0 /)$.
1 Graduate Institute of Sports Training, College of Kinesiology, University of Taipei, Taipei 11153, Taiwan; skyfu218@gmail.com (S.-K.F.); danatai1008@gmail.com (H.-L.T.)

2 Department of Exercise and Health Sciences, College of Kinesiology, University of Taipei, Taipei 11153, Taiwan; speedceng@gmail.com (W.-C.T.); fossil0405@yahoo.com.tw (K.-W.T.); sports_injury0406@yahoo.com.tw (C.-C.L.)

3 Institute of Biochemistry and Molecular Biology, College of Life Sciences, National Yang-Ming Chiao-Tung University, Taipei 112304, Taiwan; tsaiyc@ym.edu.tw

4 Department of Otorhinolaryngology, Taipei City Hospital, Taipei 10341, Taiwan

* Correspondence: Daz10@tpech.gov.tw

\begin{abstract}
A half-marathon (HM) is a vigorous high-intensity exercise, which could induce lower extremity musculoskeletal injury risks for recreational runners. They usually consume nonsteroidal antiinflammatory drugs (NSAIDs) in order to shorten their return to play but ignore the side effects, such as peptic ulcers and renal and vascular disorders. Lactobacillus plantarum PS128 (PS128) could improve inflammation and oxidative stress by modulating the gut microbiota, thus potentially improving muscle damage and recovery. However, few studies have addressed the PS128 exercise capacity recovery $96 \mathrm{~h}$ after HM. Thus, this study aimed to investigate the effect of PS128 on exercise capacity and physiological adaptation after HM. A double-blind, randomized, placebo-controlled, counterbalanced, crossover trial was used for the experiment. HM was conducted at the beginning and end of the 4-week nutritional supplement administration. Eight recreational runners took two capsules $\left(3 \times 10^{10}\right.$ CFU/capsule) of PS128 each morning and evening before meals for 4 weeks as the PS128 treatment (LT), or they took two capsules of placebo for 4 weeks as the placebo treatment (PT). In both treatments, an exercise capacity test (lower extremity muscle strength, anaerobic power, lower extremity explosive force, and aerobic capacity) and blood test (muscle fatigue, muscle damage, oxidative stress, and renal injury) were performed before the administration of the nutritional supplement (baseline), $48 \mathrm{~h}$ before HM (pre), and $0 \mathrm{~h}$ ( $0 \mathrm{~h}$ post), $3 \mathrm{~h}$ ( $3 \mathrm{~h}$ post), $24 \mathrm{~h}$ ( $24 \mathrm{~h}$ post), $48 \mathrm{~h}$ ( $48 \mathrm{~h}$ post), $72 \mathrm{~h}$ (72 h post), and $96 \mathrm{~h}$ ( $96 \mathrm{~h}$ post) after HM. There was no significant difference in the total duration of HM between PT and LT, but PT was found to be significantly higher than LT at Stage 4 (15,751-21,000 m) of HM (3394 \pm 727 s vs. $2778 \pm 551 \mathrm{~s}, p=0.02$ ). The lower extremity muscle strength measured using an isokinetic dynamometer in PT was significantly lower than that in LT at $72 \mathrm{~h}$ after HM. The lower extremity explosive force from the countermovement jump (CMJ) in PT was significantly decreased compared to $24 \mathrm{~h}$ prior. There was no significant difference between anaerobic power and aerobic capacity between the two treatments after HM. After HM, LT had lower muscle damage indices, such as myoglobin ( $3 \mathrm{~h}$ post-PT vs. -LT: $190.6 \pm 118 \mathrm{ng} / \mathrm{mL}$ vs. $91.7 \pm 68.6 \mathrm{ng} / \mathrm{mL}, p<0.0001$ ) and creatine phosphokinase ( $24 \mathrm{~h}$ post-PT vs. $-\mathrm{LT}$ : $875.8 \pm 572.3 \mathrm{IU} / \mathrm{L}$ vs. $401 \pm 295.7 \mathrm{IU} / \mathrm{L}, p<0.0001$ ). Blood urea nitrogen recovered in $24 \mathrm{~h}$ ( $24 \mathrm{~h}$ pre- vs. post-LT, $p>0.05)$ and higher superoxide dismutase was found in LT (96 h post-PT vs. -LT: $0.267 \pm 0.088 \mathrm{U} / \mathrm{mL}$ vs. $0.462 \pm 0.122 \mathrm{U} / \mathrm{mL}, p<0.0001$ ). In conclusion, PS128 supplementation was associated with an improvement in muscle damage, renal damage, and oxidative stress caused by HM through microbiota modulation and related metabolites but not in exercise capacity.
\end{abstract}

Keywords: L. plantarum PS128; muscle damage; exercise capacity recovery; half-marathon; gastrointestinal microbiota 


\section{Introduction}

Running is a popular sporting activity that can provide physical and psychological benefits to runners. However, long-distance running could induce lower extremity musculoskeletal injury risks. Prolonged running has been reported to contribute to muscular strength decline, increased creatine phosphokinase (CPK), delayed onset muscle soreness (DOMS), fatigue [1,2], and acute or chronic imbalance in multiple aspects of the human body [3].

Most muscle damage induced by exercise is due to increased oxidative stress, which results in a decrease in skeletal function [4]. Vigorous long-distance running also increases oxygen consumption, ischemia-reperfusion injury, white blood cell activation, inflammation, and reactive oxygen species (ROS) production $[5,6]$.

Overuse of the lower extremity could lead to microtrauma [7], which triggers inflammatory responses, and the accumulative effects could lead to muscle injury and dysfunction [8]. Therefore, many athletes in endurance sports consume nonsteroidal anti-inflammatory drugs (NSAIDs) [9]. Although NSAIDs have anti-inflammatory and analgesic effects, they may cause side effects, such as peptic ulcers and renal and vascular disorders [10].

Therefore, it is necessary to find a strategy to reduce muscle damage and promote recovery with fewer side effects for runners. As defined by the Food and Agriculture Organization of the United Nations and World Health Organization, probiotics are "live microorganisms which when administered in adequate amounts confer a health benefit on the host" [11]. Probiotic strains with demonstrated health benefits belong primarily to the following genera: Lactobacillus, Bifidobacterium, Saccharomyces, Enterococcus, Streptococcus, Pediococcus, Leuconostoc, Bacillus, and Escherichia [12]. Probiotics have been shown to have strain-specific effects; for example, L. casei may improve the symptoms associated with rheumatoid arthritis [13], Bifidobacterium bifidum may reduce acute diarrhea and shorten the duration of hospitalization due to acute diarrhea in children [14], and Saccharomyces boulardi is effective in the treatment of acute gastroenteritis in children [15]. Therefore, the identification of specific strains is crucial.

Gastrointestinal health could be critical for the regulation of exercise adaptation to deal with diarrhea, nausea, and abdominal cramps during prolonged and exhaustive exercise. Probiotic supplements have been shown to improve the frequency, severity, and duration of respiratory infections and gastrointestinal diseases, which may be achieved through the interaction between the gut microbiota and the immune system [16]. In 2016, Jäger et al. administered two probiotic strains (Bifidobacterium breve BR03 and Streptococcus thermophilus FP4) to 16 healthy men who habitually performed resistance training for 21 days, and theyconducted eccentric contraction of the elbow flexor muscle injury intervention. It was found that the average maximum torque of isometric contraction between IL-6 and the elbow flexor was better than that of the placebo group within $72 \mathrm{~h}$ after the intervention of the muscle injury [17]. Some studies on probiotics have demonstrated the benefits of lactobacilli in sports science. L. plantarum TWK10 has been found to improve exercise capacity by restoring energy and facilitating muscle adaption in both clinical and preclinical studies $[18,19]$. L. helveticus lafti L10 has been demonstrated to improve mucosal immune response in elite athletes in addition to alleviating upper respiratory tract infection [13]. Lactococcus lactis JCM 5805 has been proven to alleviate upper respiratory tract infection without affecting the biomarkers of muscle damage and oxidative stress [20]. The two probiotic strains, L. rhamnosus IMC 501 and L. paracasei IMC 502, can improve the oxidative stress caused by the 4-week intensive training intervention [21]. Recreationally trained males consumed $20 \mathrm{~g}$ of casein plus 1 billion CFU B. coagulans GBI-30, 6086 daily for 2 weeks, resulting in reduced exercise-induced muscle damage and increased recovery [22]. It could enhance the adaptation rate to training and subsequently lead to a faster increase in hypertrophy and performance.

Lactobacillus is the predominant genus, which has $>100$ species and is rich in carbohydrates. Most lactobacilli are isolated from the gastrointestinal tract of humans and 
animals, as well as from vegetables and fermented foods. The members are Gram-positive, nonmotile, non-spore-forming, and acid-tolerant facultative anaerobes [23]. Lactobacillus sp. is regarded as a probiotic due to its health benefits for the human body, as demonstrated in several studies, for example, the improvement in type 2 diabetes mellitus [24], blood pressure [25], as well as anti-inflammatory and antioxidant effects [26,27]. Lactobacillus plantarum PS128 (PS128) isolated from fu-tsai, a traditional Taiwanese fermented vegetable food product [28], has been found to improve behavioral performance in patients with autism spectrum disorder [29]; it also exhibits anti-inflammatory and immune system regulatory effects [30] and helps control neuropsychiatric diseases by decreasing anxiety-like behaviors [31]. In recent studies, PS128 has been shown to be effective in decreasing the level of muscle damage, oxidative stress, and inflammatory symptoms caused by longterm exercise in endurance athletes [32]. PS128 supplementation modulated the athlete's microbiota with significant decreases in Anaerotruncus, Caproiciproducens, Coprobacillus, Desulfovibrio, Dielma, Family_XIII, Holdemania, and Oxalobacter and increases in Akkermansia, Bifidobacterium, Butyricimonas, and Lactobacillus, and they showed more diversity [33]. Short-chain fatty acids (SCFAs) increased after the administration of PS128, which might be a result of the modulation of the associated microbiota.

However, there has been no study investigating whether long-term PS128 consumption in recreational runners decreases the level of muscle damage and promotes the recovery of exercise capacity after HM. Therefore, in this study, we evaluated the recovery of exercise capacity and the level of muscle damage in recreational runners with placebo and PS128 intake after HM.

\section{Materials and Methods}

\subsection{Lactic Acid Bacteria}

Lactobacillus plantarum PS128 was stored at the DSMZ German Collection of Microorganisms and Cell Cultures with the accession number DSM 28632. It was manufactured by Bened Biomedical Co., Ltd. (Taipei City, Taiwan) in the dosage form of capsules containing milky white powder. Each capsule weighed $425 \pm 25 \mathrm{mg}$ and contained $3 \times 10^{10} \mathrm{CFU}$ of PS128 in the shell of the microcrystalline cellulose. The product was stored at $4-8{ }^{\circ} \mathrm{C}$. The placebo treatment (PT) received the same type of capsules filled with $425 \pm 25 \mathrm{mg}$ microcrystalline cellulose.

\subsection{Participants}

Eight recreational runners (four males: age: $27.0 \pm 2.3$ years; height: $176.8 \pm 2.4 \mathrm{~cm}$; weight: $77.7 \pm 8.5 \mathrm{~kg}$; BMI: $24.8 \pm 2.4 \mathrm{~kg} / \mathrm{m} 2$ and four females: age: $24.0 \pm 0.8$ years; height: $162.0 \pm 4.3 \mathrm{~cm}$; weight: $55.5 \pm 1.0 \mathrm{~kg}$; BMI: $21.2 \pm 0.8 \mathrm{~kg} / \mathrm{m} 2)$ were included in the study. The participants had not undergone regular resistance training, aerobic exercise, or flexibility training in the past year; did not carry heavy things frequently; and did not have musculoskeletal injury. They were requested to maintain a normal daily routine within $48 \mathrm{~h}$ before trial-related activity and were prohibited from strenuous exercise, smoking, alcoholic beverage intake, or staying up late. During the use of PS128, the participants were prohibited from consuming other probiotics, such as fermented products (e.g., Yakult and yogurt), vitamins, minerals, Chinese medicine, and antibiotics. Participants who succeeded in the initial screening were informed of the study objectives, procedures, and potential risks, and written informed consent was obtained from them. The study was conducted according to the Declaration of Helsinki after obtaining approval from the institutional review board of the University of Taipei (approval no.: Taipei, Taiwan; no. IRB-2020-054).

\subsection{Experimental Design}

A double-blind, randomized, placebo-controlled, counterbalanced, crossover trial was used for the experiment. The period of nutritional supplementation was 4 weeks, in accordance with previous studies [21,32]. HM was conducted at the end of the 4-week nutritional supplementation. Participants took 2 capsules $\left(3 \times 10^{10} \mathrm{CFU} /\right.$ capsule) of PS128 
each morning and evening before meals for 4 weeks as the PS128 treatment (LT, $n=8)$, or they took 2 capsules of placebo for 4 weeks as the PT $(n=8)$ in the control. After HM, an exercise capacity test, a blood test, and a 3-month washout period were conducted. The nutritional supplements taken by LT and PT were exchanged and taken for 4 weeks, and $\mathrm{HM}$, an exercise capacity test, and a blood test were performed again.

The muscle damage caused by EIMD could last for approximately $96 \mathrm{~h}$. Thus, in order to observe the period of return to play, in both treatments, an exercise capacity test and blood sampling were performed before nutritional supplement administration (baseline), $48 \mathrm{~h}$ before HM (pre), and $0 \mathrm{~h}$ ( 0 h post), $3 \mathrm{~h}$ ( $3 \mathrm{~h}$ post), $24 \mathrm{~h}$ ( $24 \mathrm{~h}$ post), $48 \mathrm{~h}$ ( $48 \mathrm{~h}$ post), $72 \mathrm{~h}$ (72 h post), and $96 \mathrm{~h}$ (96 h post) after HM (Figure 1). The exercise capacity assessment included lower extremity muscle strength, anaerobic power (except for $0 \mathrm{~h}$ post), lower extremity explosive force, and aerobic capacity (only at pre, $24 \mathrm{~h}$ post, and $96 \mathrm{~h}$ post) tests. Blood samples were used to analyze the biomarkers for muscle fatigue, muscle damage, oxidative stress, and renal injury.

A Experiment design

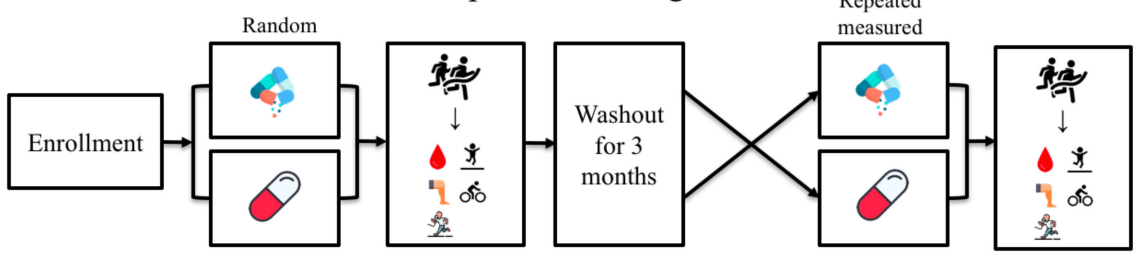

B

Experiment timeline

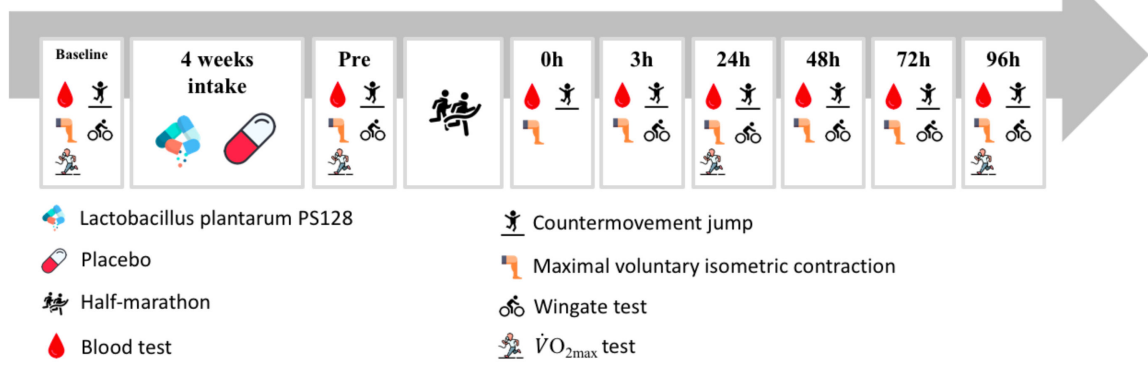

Figure 1. Experimental design flowchart. Experiment design (A): A double-blind, randomized, placebo-controlled, counterbalanced, crossover trial was used for the experiment. The period of nutritional supplementation was 4 weeks. Half-marathon (HM) was conducted at the end of the 4-week nutritional supplementation. Participants took 2 capsules of Lactobacillus plantarum PS128 (PS128) each morning and evening before meals for 4 weeks as the PS128 treatment (LT, $n=8)$, or they took 2 capsules of placebo for 4 weeks as the placebo treatment (PT, $n=8)$ in the control. After $\mathrm{HM}$, an exercise capacity test, a blood test, and a 3-month washout period were conducted. Then, the two treatments were exchanged, and subsequent interventions and detection were performed. Experiment timeline (B): Baseline, pre, 0 h, $3 \mathrm{~h}, 24 \mathrm{~h}, 48 \mathrm{~h}, 72 \mathrm{~h}$, and $96 \mathrm{~h}$ indicate the stage before the administration of the nutritional supplement, $48 \mathrm{~h}$ before the half-marathon intervention, immediately after the half-marathon intervention, $3 \mathrm{~h}$ after the half-marathon intervention, $24 \mathrm{~h}$ after the halfmarathon intervention, $48 \mathrm{~h}$ after the half-marathon intervention, $72 \mathrm{~h}$ after the half-marathon intervention and $96 \mathrm{~h}$ after the half-marathon intervention, respectively.

\subsection{Half-Marathon}

At the Tianmu campus of the University of Taipei, equipped with a standard $400 \mathrm{~m}$ track and field stadium made of polyurethane (PU), all participants jogged for 5 min and carried out a 15 min dynamic warm-up before HM at $5 \mathrm{am}$. The total distance was $21 \mathrm{~km}$, and the time was recoded every $5 \mathrm{~km}$ and $250 \mathrm{~m}$, for a total of 4 time divisions (Stage 1: 0-5250 m; Stage 2: 5251-10,500 m; Stage 3: 10,501-15,750 m; Stage 4: 15,751-21,000 m). A station was placed at the $50 \mathrm{~m}$ point from the starting line to provide water and first-aid services, where emergency medical technicians were stationed to monitor the whole course. 


\subsection{Lower Extremity Muscle Strength Test}

For lower extremity muscle strength testing, an isokinetic dynamometer (Biodex System Pro 4; Biodex Medical Systems, Shirley, NY, USA) was used to measure the maximal voluntary isometric contraction (MVIC) of knee extensors and flexors. Participants were familiarized with MVIC test procedures 2 weeks before their test. At a sitting position (hip flexion $85^{\circ}$ ), with knee flexion $30^{\circ}$ over the dominant side and the shoulders, chest, hip, and thigh over the nondominant side fixed with straps, a participant was asked to perform knee extensor MVICs for $3 \mathrm{~s}$ with the dominant leg (defined as the leg the participant chooses to kick a ball with) (Montgomery and Shultz 2010) at the maximal exertion. The test was repeated thrice, with a 1 min interval between the two attempts. A knee flexors test was conducted, 5 min after the knee extensors test, at a sitting position (hip flexion $85^{\circ}$ ), with a knee flexion of $60^{\circ}$ over the dominant side. Participants were encouraged and instructed orally by the study staff during their tests to ensure MVIC was achieved in each contraction [34]. Test results were analyzed by the Biodex System Pro 4 Curve Analysis software. Lower extremity muscle strength was presented as the peak torque per $\mathrm{kg}$ of body weight $(\mathrm{Nm})$, and the maximum value among the three attempts was considered.

\subsection{Anaerobic Power Test}

The $30 \mathrm{~s}$ Wingate Anaerobic Test was conducted to determine the anaerobic power (W. $\left.\mathrm{kg}^{-1}\right)$, such as anaerobic peak power, anaerobic mean power, and fatigue index [35]. A bicycle dynamometer, Cyclus 2 (Avantronics Cyclus 2, Leipzig, Germany), was used, and the resistance coefficient was adjusted according to the sex and weight of the participants (male: weight $\times 0.8$; female: weight $\times 0.77$ ). The bicycle dynamometer seat was set at the most appropriate height where a participant's knee joint could be kept at $30^{\circ}$ flexion when the pedal of the same side was set at the lowest position. Participants were asked to pedal at 60 revolutions per minute (rpm) without resistance for $2 \mathrm{~min}$ before the test started. The study staff counted down from $10 \mathrm{~s}$ before the initiation of the actual test to alert the participants. During the actual test, the study staff encouraged the participants to reach their highest possible rpm.

\subsection{Lower Extremity Explosive Force Test}

The countermovement jump (CMJ) was used to test the explosive force of the lower extremities of the participants, and the values were defined by the height of the jump they could perform. A BTS force plate (P6000, BTS Bioengineering, Milano, Italy), fixed on the floor, was used for this test. A computer was connected to the force plate to collect the data. The jump height was calculated by introducing the flight time into the jump height formula using Microsoft Excel 2016 [36].

\subsection{Aerobic Capacity Test}

The Bruce maximal aerobic capacity test was conducted; the participants ran on a highspeed treadmill (H/P COSMOS Pulsar 3P, Nussdorf-Traunstein, Germany) [37] at pre, $24 \mathrm{~h}$ post, and $96 \mathrm{~h}$ post stages. The values were presented as the maximum oxygen consumption, measured by a cardiopulmonary exercise tester (Cosmed Quark CPET system; Rome, Italy). The test was initiated once a participant on the treadmill showed a sign of stable heart beats. The speed and slope started at $2.7 \mathrm{~km} / \mathrm{h}$ and $10 \%$ and then were adjusted every $3 \mathrm{~min}$ according to the following settings: $4.0 \mathrm{~km} / \mathrm{h}$ and $12 \%, 5.5 \mathrm{~km} / \mathrm{h}$ and $14 \%, 6.8 \mathrm{~km} / \mathrm{h}$ and $16 \%, 8.0 \mathrm{~km} / \mathrm{h}$ and $18 \%, 8.9 \mathrm{~km} / \mathrm{h}$ and $20 \%, 9.7 \mathrm{~km} / \mathrm{h}$ and $22 \%$, and $10.5 \mathrm{~km} / \mathrm{h}$ and $24 \%$ (end of test). To ensure that participants exerted their maximal effort, the test results should meet two of the following three criteria: (1) voluntary request to stop the test, (2) respiratory exchange ratio of $>1.15$, and (3) oxygen consumption change of $\leq 2 \mathrm{~mL} \cdot \mathrm{kg}^{-1} \cdot \mathrm{min}^{-1}$ from a lower-intensity to higher-intensity test level [38]. 


\subsection{Blood Sampling}

Blood samples were collected from the hand veins of the upper extremities at baseline, pre, $0 \mathrm{~h}$ post, $3 \mathrm{~h}$ post, $24 \mathrm{~h}$ post, $48 \mathrm{~h}$ post, $72 \mathrm{~h}$ post, and $96 \mathrm{~h}$ post stages to analyze muscle fatigue indicators, such as branched-chain amino acids (BCAA) and ammonia $\left(\mathrm{NH}_{3}\right)$; muscle damage indicators, such as myoglobin, lactate dehydrogenase (LDH), and creatinine phosphokinase (CPK); renal injury indicators, such as blood urea nitrogen (BUN); and oxidative stress indicators, such as superoxide dismutase (SOD) and catalase (CAT). The blood samples were collected in tubes and centrifuged to obtain plasma and serum. Collection tubes containing anticoagulant heparin were used to obtain plasma, and those without anticoagulants were used to obtain serum. The plasma and serum were stored at $-70{ }^{\circ} \mathrm{C}$ for further analysis.

\subsection{Biochemical Variables}

$\mathrm{NH}_{3}, \mathrm{LDH}, \mathrm{CPK}$, and BUN in the serum were detected using a Beckman Coulter UniCel DxC 800 Automatic Biochemical Analyzer (Beckman Coulter, Fullerton, CA, USA). Myoglobin was detected using a Beckman Coulter UniCel Dxl 810 Automatic Biochemical Analyzer (Beckman Coulter, Fullerton, CA, USA). The activities of SOD and CAT were assayed in the serum samples by using commercial kits (SOD: Cayman Chemicals Inc., 706002, Ann Arbour, MI, USA; CAT: Cayman Chemicals Inc., 707002, Ann Arbour, MI, USA), following the manufacturer's instructions. The activities of SOD and CAT were calculated using an equation obtained from the linear regression of the standard curve. BCAA in the serum were quantified using a commercial colorimetric kit (BioVision, K564100, Milpitas, CA, USA), following the manufacturer's instructions. All samples and standards were measured in duplicate.

\subsection{Statistical Analysis}

The mean \pm SD was used to describe all dependent variables. All statistical tests were conducted using GraphPad Prism (Version 8; GraphPad Software, San Diego, CA, USA) and Excel 2016, with statistical significance set at $p \leq 0.05$. The normality assumption for each variable was verified using the Shapiro-Wilk test, which confirmed the normal distribution of data. A prior evaluation of the homogeneity of variance and sphericity was conducted using Levene's test and Mauchly's test, respectively. Consequently, a mixed analysis of variance (ANOVA) was applied to examine the changes in each variable over time between the two treatments, considering the within-subject factor time (pre, $0 \mathrm{~h}$ post, $3 \mathrm{~h}$ post, $24 \mathrm{~h}$ post, $48 \mathrm{~h}$ post, $72 \mathrm{~h}$ post, and $96 \mathrm{~h}$ post) and the between-subject factor group (LT and PT). Follow-up statistical tests included one-way repeated-measures ANOVA with Tukey's post hoc test and pairwise comparisons with Sidak adjustments. To avoid individual variation, the measurements of exercise performance were normalized to the percentage of the premeasurement (posttest/pretest) $\times 100 \%$ for comparison. The results are shown as the percentage $(\%) \pm$ standard deviation (\%).

\section{Results}

\subsection{Test of Homogeneity}

The results of a test of homogeneity are shown in Table 1 . Mean \pm SD was used to describe all dependent variables. All statistical tests were conducted using Excel 2016 with statistical significance set at $p \leq 0.05$. The results of the $t$-test show that there was no significant difference between the PT and LT at baseline.

Comparing the exercise capacity and blood test from pre-PT and pre-LT, Mean $\pm \mathrm{SD}$ was used to describe all dependent variables. All statistical tests were conducted using Excel 2016 with statistical significance set at $p \leq 0.05$. The results of the $t$-test showed that there was no significant difference between the two treatments in various indicators (Table 2). 
Table 1. Test of homogeneity.

\begin{tabular}{|c|c|c|c|}
\hline Exercise Capacity and Blood Samples & $\begin{array}{l}\text { Baseline PT } \\
\quad(n=8)\end{array}$ & $\begin{array}{l}\text { Baseline LT } \\
\quad(n=8)\end{array}$ & $p$-Value \\
\hline \multicolumn{4}{|l|}{ Lower extremity muscle strength } \\
\hline knee extensor peak torque $(\mathrm{N}-\mathrm{m} / \mathrm{kg})$ & $3.21 \pm 0.88$ & $3.08 \pm 0.84$ & 0.38 \\
\hline knee flexor peak torque $(\mathrm{N}-\mathrm{m} / \mathrm{kg})$ & $1.23 \pm 0.35$ & $1.15 \pm 0.31$ & 0.33 \\
\hline \multicolumn{4}{|l|}{ Anaerobic capacity } \\
\hline anaerobic peak power $(\mathrm{w} / \mathrm{kg})$ & $10.06 \pm 1.66$ & $10 \pm 1.37$ & 0.47 \\
\hline anaerobic mean power $(\mathrm{w} / \mathrm{kg})$ & $7.05 \pm 1.23$ & $7.16 \pm 1.47$ & 0.44 \\
\hline fatigue index & $14.95 \pm 5.49$ & $14.24 \pm 3.32$ & 0.38 \\
\hline \multicolumn{4}{|l|}{ Explosive force of the lower extremities } \\
\hline $\begin{array}{l}\text { CMJ height }(\mathrm{cm}) \\
\text { Muscle fatigue }\end{array}$ & $32 \pm 7.86$ & $27.38 \pm 11.49$ & 0.18 \\
\hline $\mathrm{BCAA}(\mathrm{nmol} / \mathrm{ul})$ & $0.33 \pm 0.07$ & $0.34 \pm 0.04$ & 0.29 \\
\hline $\mathrm{NH}_{3}(\mu \mathrm{mol} / \mathrm{L})$ & $35.63 \pm 20.56$ & $28.25 \pm 6.48$ & 0.18 \\
\hline Myoglobin (ng/mL) & $23.79 \pm 9.65$ & $29.72 \pm 30.73$ & 0.31 \\
\hline $\mathrm{LDH}(\mathrm{IU} / \mathrm{L})$ & $132.25 \pm 8.92$ & $132 \pm 21.47$ & 0.49 \\
\hline CPK (IU/L) & $168.25 \pm 125.41$ & $188.13 \pm 233.09$ & 0.42 \\
\hline \multicolumn{4}{|l|}{ Renal injury } \\
\hline $\mathrm{BUN}(\mathrm{mg} / \mathrm{dL})$ & $10.22 \pm 3.14$ & $10.79 \pm 3.25$ & 0.36 \\
\hline \multicolumn{4}{|l|}{ Anti-oxidative capacity } \\
\hline $\mathrm{SOD}(\mathrm{U} / \mathrm{mL})$ & $0.11 \pm 0.09$ & $0.16 \pm 0.06$ & 0.10 \\
\hline $\mathrm{CAT}(\mathrm{nmol} / \mathrm{min} / \mathrm{mL})$ & $64.88 \pm 28.24$ & $67.8 \pm 24.9$ & 0.41 \\
\hline
\end{tabular}

The data are represented as mean \pm standard deviation. Placebo treatment (PT); Lactobacillus plantarum PS128 treatment (LT); baseline is the time point before taking nutritional supplements; countermovement jump (CMJ); branched-chain amino acid (BCAA); blood ammonia $\left(\mathrm{NH}_{3}\right)$; lactate dehydrogenase (LDH); creatine phosphokinase (CPK); blood urea nitrogen (BUN); superoxide dismutase (SOD); catalase (CAT). $p<0.05$ was considered to be a statistically significant difference between the groups.

Table 2. Comparison of exercise capacity and blood test between PT and LT after taking nutritional supplements for 4 weeks.

\begin{tabular}{|c|c|c|c|}
\hline & $\begin{array}{l}\text { Pre-PT } \\
(n=8)\end{array}$ & $\begin{array}{l}\text { Pre-LT } \\
(n=8)\end{array}$ & $p$-Value \\
\hline \multicolumn{4}{|l|}{ Lower extremity muscle strength } \\
\hline knee extensor peak torque $(\mathrm{N}-\mathrm{m} / \mathrm{kg})$ & $3.1 \pm 0.82$ & $3.07 \pm 0.84$ & 0.47 \\
\hline knee flexor peak torque $(\mathrm{N}-\mathrm{m} / \mathrm{kg})$ & $1.21 \pm 0.36$ & $1.14 \pm 0.29$ & 0.32 \\
\hline \multicolumn{4}{|l|}{ Anaerobic capacity } \\
\hline anaerobic peak power $(\mathrm{w} / \mathrm{kg})$ & $10.04 \pm 1.6$ & $10.07 \pm 1.5$ & 0.48 \\
\hline anaerobic mean power $(\mathrm{w} / \mathrm{kg})$ & $7.06 \pm 1.3$ & $7.04 \pm 1.54$ & 0.49 \\
\hline fatigue index & $14.88 \pm 5.38$ & $14.61 \pm 3.91$ & 0.46 \\
\hline \multicolumn{4}{|l|}{ Explosive force of the lower extremities } \\
\hline $\begin{array}{l}\text { CMJ height }(\mathrm{cm}) \\
\text { Muscle fatigue }\end{array}$ & $31.86 \pm 8.04$ & $31.94 \pm 8.07$ & 0.49 \\
\hline BCAA (nmol/ul) & $0.33 \pm 0.07$ & $0.33 \pm 0.04$ & 0.49 \\
\hline $\mathrm{NH}_{3}(\mu \mathrm{mol} / \mathrm{L})$ & $35.25 \pm 20.81$ & $27.63 \pm 6.55$ & 0.18 \\
\hline \multicolumn{4}{|l|}{ Muscle damage } \\
\hline Myoglobin (ng/mL) & $23.98 \pm 10.04$ & $29.76 \pm 30.73$ & 0.31 \\
\hline $\mathrm{LDH}(\mathrm{IU} / \mathrm{L})$ & $131.13 \pm 10.53$ & $131.25 \pm 21.59$ & 0.49 \\
\hline CPK (IU/L) & $167.5 \pm 125.62$ & $187.38 \pm 233.51$ & 0.42 \\
\hline \multicolumn{4}{|l|}{ Renal injury } \\
\hline $\mathrm{BUN}(\mathrm{mg} / \mathrm{dL})$ & $10.24 \pm 3.18$ & $10.86 \pm 3.32$ & 0.35 \\
\hline \multicolumn{4}{|l|}{ Anti-oxidative capacity } \\
\hline $\mathrm{SOD}(\mathrm{U} / \mathrm{mL})$ & $0.13 \pm 0.09$ & $0.15 \pm 0.05$ & 0.29 \\
\hline $\mathrm{CAT}(\mathrm{nmol} / \mathrm{min} / \mathrm{mL})$ & $62.48 \pm 42.97$ & $57.81 \pm 33.9$ & 0.41 \\
\hline
\end{tabular}

The data are represented as mean \pm standard deviation. Placebo treatment (PT); Lactobacillus plantarum PS128 treatment (LT); pre represents the time point of $48 \mathrm{~h}$ before the half-marathon intervention; countermovement jump (CMJ); branched-chain amino acid (BCAA); blood ammonia $\left(\mathrm{NH}_{3}\right)$; lactate dehydrogenase $(\mathrm{LDH})$; creatine phosphokinase $(\mathrm{CPK})$; blood urea nitrogen (BUN); superoxide dismutase (SOD); catalase (CAT). $p<0.05$ was considered to be a statistically significant difference between the groups. 


\subsection{Half-Marathon}

The environmental conditions during HM were as follows for PT $(n=4)$ and LT $(n=4)$ : $17.6-18.1{ }^{\circ} \mathrm{C}(05: 00 \mathrm{am} .-09: 00 \mathrm{am}$.), relative humidity of $80-86 \%$, and wind speed of 1.1-1.2 m/s. After a 3-month washout and the exchange of nutritional supplements in the two treatments, the environmental conditions during HM were as follows for PT $(n=4)$ and LT $(n=4): 17.1-17.9{ }^{\circ} \mathrm{C}(05: 00 \mathrm{am} .-09: 00 \mathrm{am}$.), relative humidity of $77-79 \%$, and wind speed of $1.0-1.1 \mathrm{~m} / \mathrm{s}$. The total duration in which the eight PT participants completed HM varied from 02:01:37 to 04:08:00 (HH:MM:SS), with a mean duration of 03:00:52 \pm 00:34:05 (02:45:44 \pm 00:29:56 in males and 03:16:00 \pm 00:34:42 in females). The total duration in which the eight LT participants completed HM varied from 01:57:09 to 03:46:58, with a mean duration of 02:46:34 \pm 00:29:55 (02:46:34 \pm 00:29:55 in males and 03:02:25 \pm 00:29:47 in females). There was no significant difference between PT and LT ( $p=0.819)$ (males undergoing PT and LT: $p=0.895$; females undergoing PT and LT: $p=0.950$; sex in PT: $p=0.316$; sex in LT: $p=0.249$ (Figure 2)).

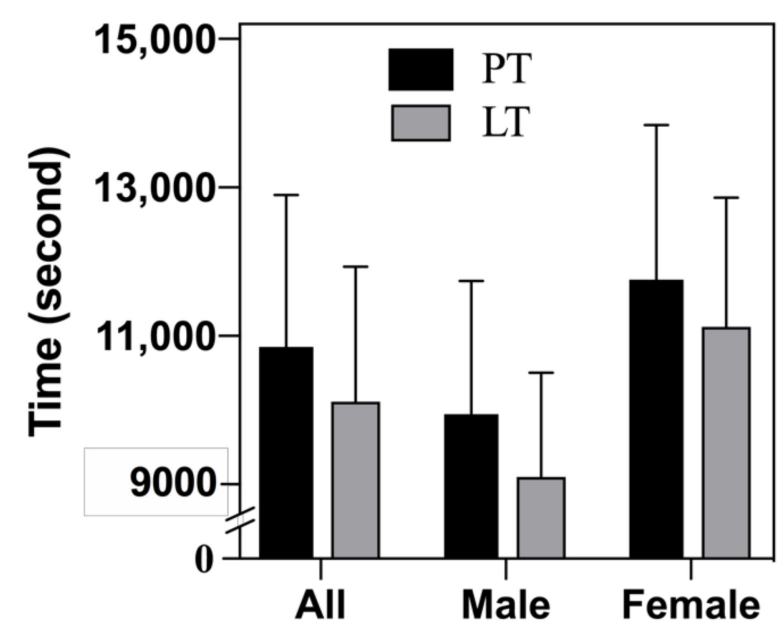

Figure 2. Comparison of the completion time of the half-marathon. The data are represented as mean \pm standard deviation. Placebo treatment (PT); Lactobacillus plantarum PS128 treatment (LT). $p<0.05$ was considered to be a statistically significant difference within and between the groups.

A two-way repeated-measures ANOVA detected that there was a significant interaction between time and stage $(p<0.0001)$ for the split time of HM. Therefore, the pairwise comparisons from Tukey multiple comparisons tests showed that the split times of HM were significantly different between Stage 1 and Stage $3(p<0.0001)$, Stage 1 and Stage 4 $(p<0.0001)$, Stage 2 and Stage $3(p<0.0001)$, Stage 2 and Stage $4(p<0.0001)$, and Stage 3 and Stage $4(p<0.0001)$. Sidak multiple comparisons tests showed that the split time of HM for PT was significantly lower than LT at Stage 4 (3394 $\pm 727 \mathrm{~s}$ vs. $2778 \pm 551 \mathrm{~s}$, $p<0.0001$ ) (Figure 3).

\subsection{Analysis of Lower Extremity Muscle Strength}

MVICs of knee extensors and flexors measured by an isokinetic dynamometer in lower extremity power test are shown in Figure 4A,B. A two-way repeated-measures ANOVA detected that there was a significant time by group interaction $(p=0.002)$ for knee extensor peak torque. Therefore, the pairwise comparisons from Tukey multiple comparisons tests showed that knee extensor peak torque decreased from the pre to $0 \mathrm{~h}$ post $(p=0.0136)$, $3 \mathrm{~h}$ post $(p<0.0001), 24 \mathrm{~h}$ post $(p<0.0001), 48 \mathrm{~h}$ post $(p=0.0004)$, and $72 \mathrm{~h}$ post $(p=0.017)$ stages in PT. The knee extensor peak torque in LT showed no significant difference after HM. Sidak multiple comparisons tests showed that the knee extensor peak torque for PT was significantly lower than that for LT at $3 \mathrm{~h}$ post $(p=0.025), 24 \mathrm{~h}$ post $(p<0.0001), 48 \mathrm{~h}$ post $(p=0.0003), 72 \mathrm{~h}$ post $(p=0.0173)$, and 96 h post $(p=0.0029)$ stages (Figure $4 \mathrm{~A})$. 


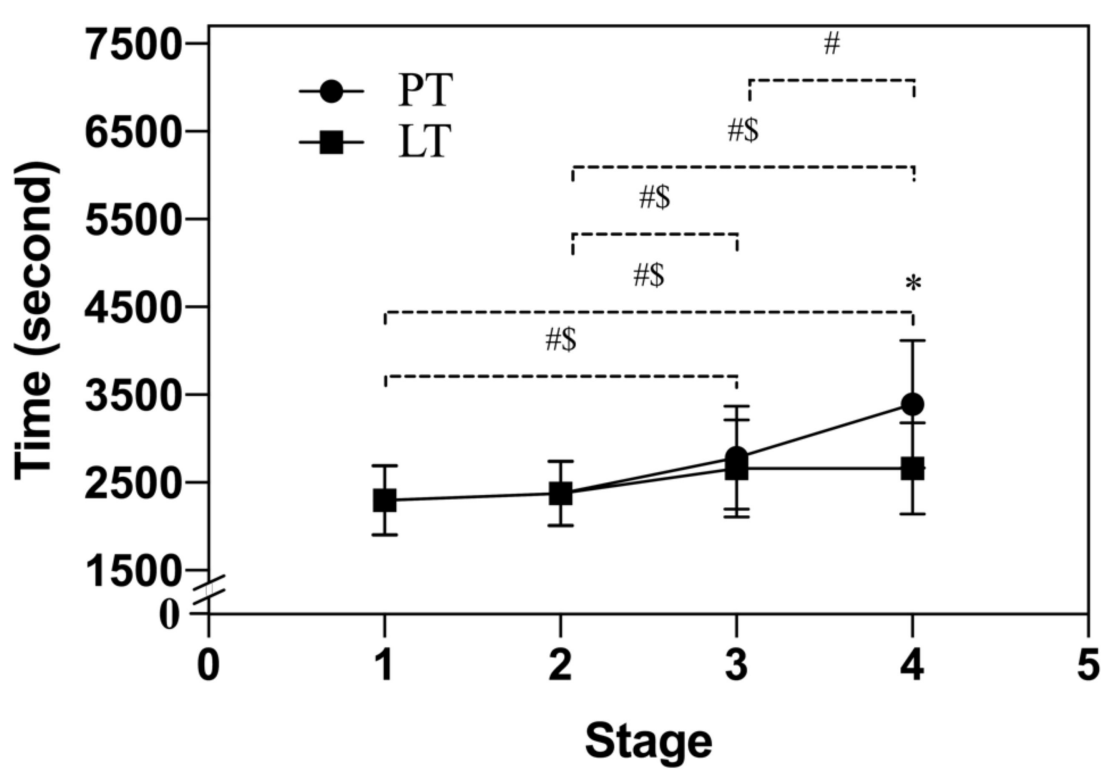

Figure 3. Comparison of the split time of the half-marathon. The data are represented as mean \pm standard deviation. Placebo treatment (PT); Lactobacillus plantarum PS128 treatment (LT). Stage 1 distance is $0-5250 \mathrm{~m}$; Stage 2 distance is $5251-10,500 \mathrm{~m}$; Stage 3 distance is 10,501-15,750 m; Stage 4 distance is $15,751-21,000 \mathrm{~m}$; * indicates a significant difference between PT and LT $(p<0.05)$; \# indicates that PT has a significant difference in split time $(p<0.05)$; $\$$ indicates that LT has a significant difference in split time $(p<0.05)$.

A two-way repeated-measures ANOVA detected that there was a significant time by group interaction $(p=0.0394)$ for knee flexor peak torque. Therefore, the pairwise comparisons from Tukey multiple comparisons tests showed that knee flexor peak torque decreased from the pre to $0 \mathrm{~h}$ post $(p=0.0075), 3 \mathrm{~h}$ post $(p=0.0256)$, and $24 \mathrm{~h}$ post $(p=0.009)$ stages in PT. The knee flexor peak torque in LT showed no significant difference after HM. Sidak multiple comparisons tests showed that the knee flexor peak torque for PT was significantly lower than that for LT at the $24 \mathrm{~h}$ post stage $(p=0.0116)$ (Figure $4 \mathrm{~B})$. In sum, LT showed less decline in the strength of knee extensors and knee flexors after HM.

\subsection{Analysis of Anaerobic Power}

Anaerobic power was tested by a $30 \mathrm{~s}$ Wingate Anaerobic Test, and the results are shown in Figure 4C-E. No significant change in the anaerobic peak power (Figure 4C), mean power (Figure 4D), or fatigue index (Figure 4E) before and after HM was observed in PT or LT.

\subsection{Analysis of Lower Extremity Muscle Explosive Force}

Lower extremity explosive force was measured by CMJ height, as shown in Figure 4F. No significant difference in lower extremity explosive force before and after HM was observed between PT and LT. However, in PT, the lower extremity explosive force at $0 \mathrm{~h}$ post, $3 \mathrm{~h}$ post, and $24 \mathrm{~h}$ post stages was significantly lower than that at the pre stage $(p<0.05)$. In LT, the result at each time point after HM did not decrease (Figure $4 \mathrm{~F})$, indicating less decline in lower extremity explosive force.

\subsection{Analysis of Aerobic Capacity and Body Composition}

The Bruce maximal aerobic capacity was tested using a high-speed treadmill and presented as maximal oxygen consumption. There were no significant changes in maximal oxygen consumption after HM in PT and LT. 
(A)

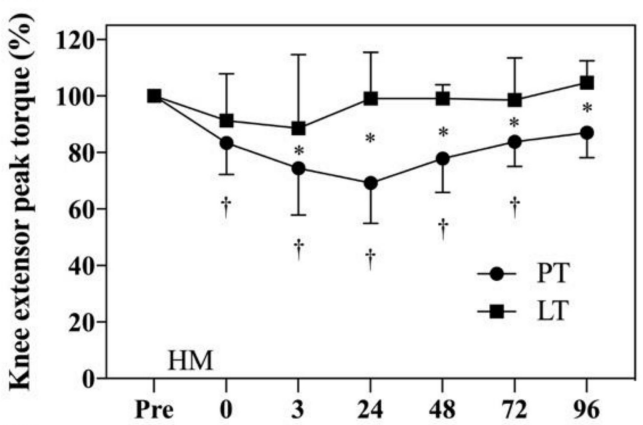

(C)

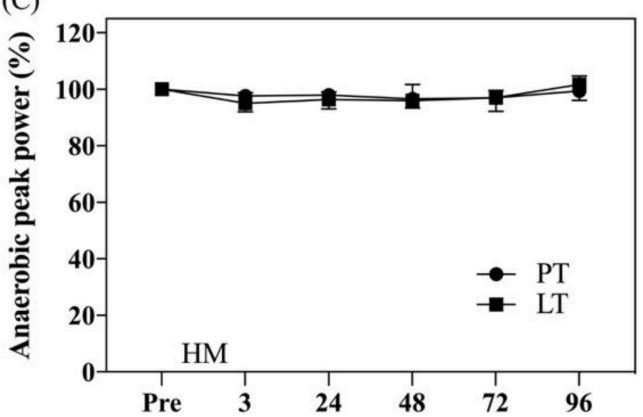

(E)

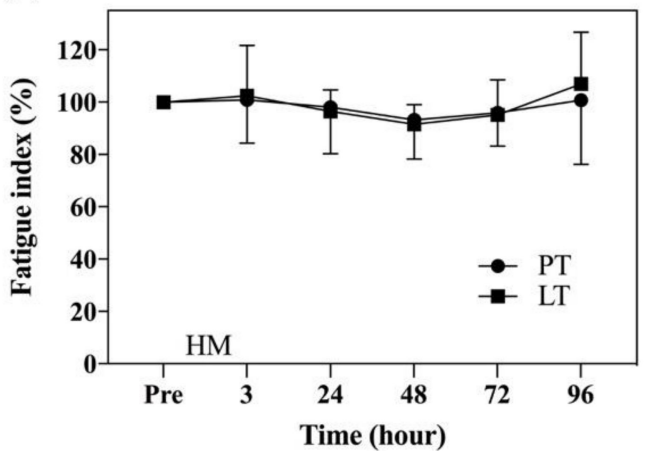

(B)

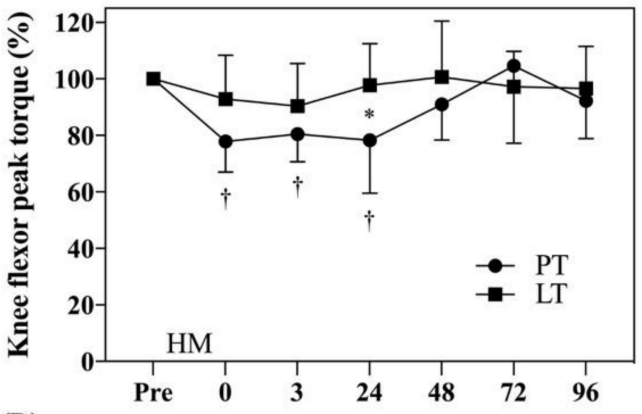

(D)

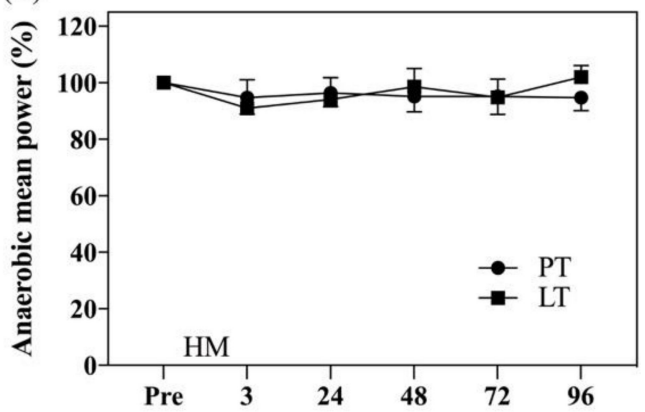

(F)

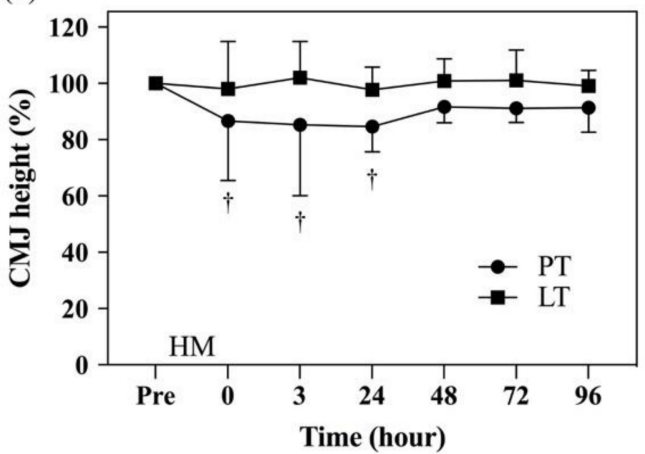

Figure 4. Comparison of normalized exercise capacity results. The data are represented as mean \pm standard deviation. Knee extensor peak torque (A); knee flexor peak torque (B); anaerobic peak power (C); anaerobic mean power (D); fatigue index (E); countermovement jump (CMJ) height (F). HM: half-marathon; † represents that there was a significant change from pre to post time points in the placebo treatment $(\mathrm{PT}) ;{ }^{*}$ represents that there was a significant difference at the same time point between PT and LT. $p<0.05$ was considered to be a statistically significant difference within and between the groups.

\subsection{Analysis of Blood Samples}

There was no significant difference in the muscle fatigue factor after HM between PT and LT (Figure 5A,B). Muscle damage indicators were significantly elevated after HM in both treatments (Figure $5 \mathrm{C}-\mathrm{E})$. Myoglobin ( $0 \mathrm{~h}$ post and $3 \mathrm{~h}$ post; Figure $5 \mathrm{C}$ ) and $\mathrm{CPK}$ ( $3 \mathrm{~h}$ post, $24 \mathrm{~h}$ post, and $48 \mathrm{~h}$ post; Figure 5E) in PT were significantly higher than those in LT, indicating apparently more serious muscle damage in PT. BUN, the indicator of renal injury, was significantly elevated after HM in both treatments, but it returned to baseline at $24 \mathrm{~h}$ post-LT (Figure 5F), indicating faster recovery. Although SOD, the indicator of antioxidation function, at $3 \mathrm{~h}$ post-, $24 \mathrm{~h}$ post-, and $48 \mathrm{~h}$ post-LT was significantly lower than that in PT $(p<0.05)$, it was significantly higher in LT than in PT at $72 \mathrm{~h}$ post and $96 \mathrm{~h}$ post stages ( $p<0.05$; Figure $5 \mathrm{G}$ ), suggesting better antioxidation function in LT. There was no significant difference in CAT at any time point between the two treatments $(p>0.05$;

Figure 5H). 
(A)

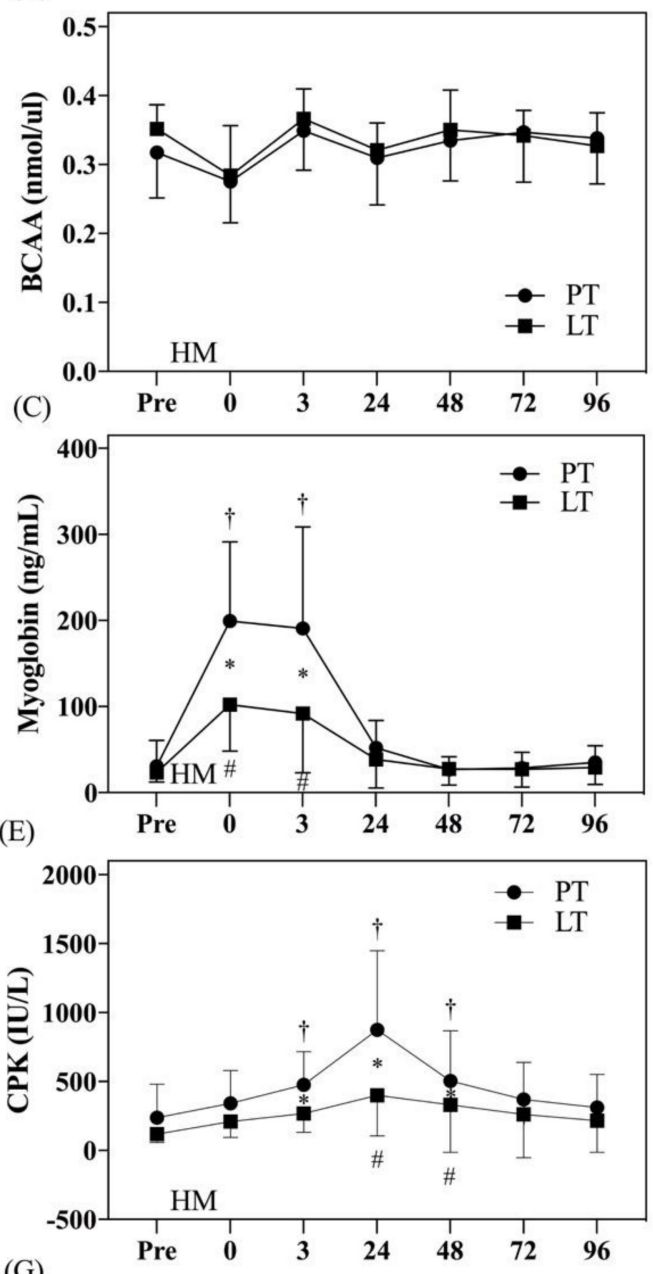

(G)

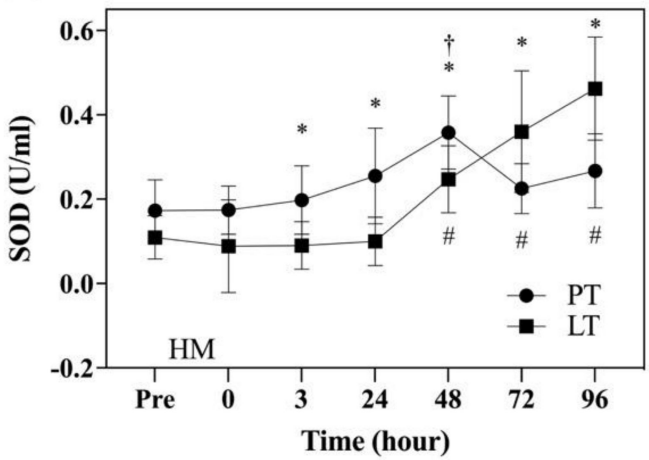

(B)

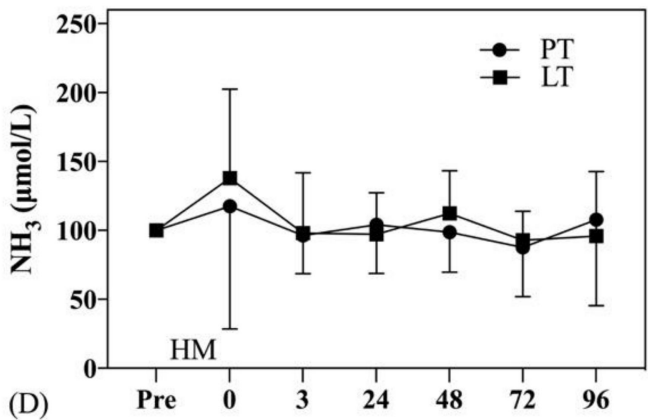

(D)

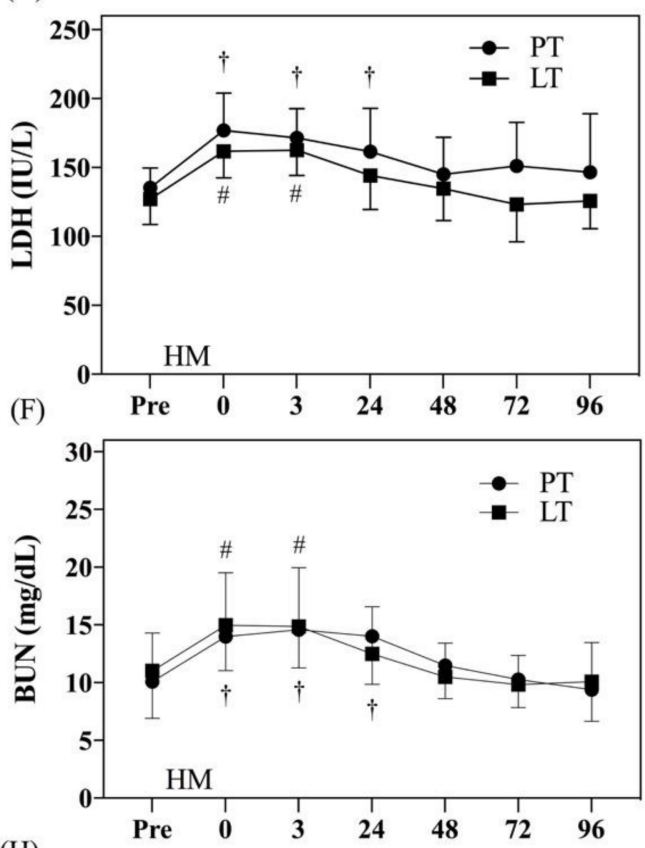

(H)

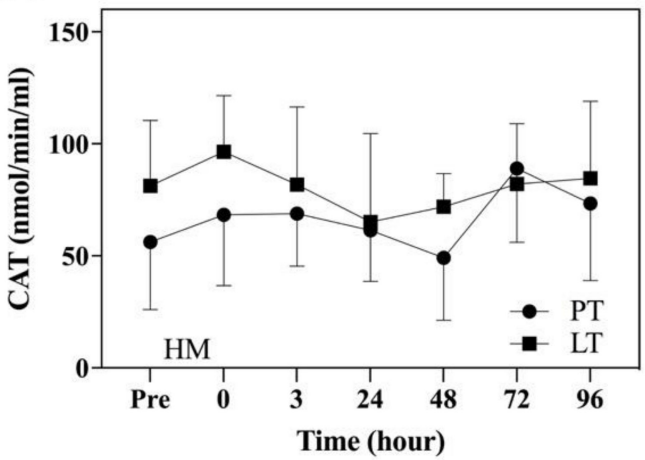

Figure 5. Comparison of blood tests. The data are represented as mean \pm standard deviation. Branched-chain amino acid (BCAA) in Figure (A); blood ammonia level $\left(\mathrm{NH}_{3}\right)$ in Figure (B); myoglobin in Figure (C); lactate dehydrogenase (LDH) in Figure (D); creatine phosphokinase (CPK) in Figure (E); blood urea nitrogen (BUN) in Figure (F); superoxide dismutase (SOD) in Figure (G); catalase (CAT) in Figure (H). • represents the placebo treatment (PT); $\mathbf{\square}$ represents the PS128 treatment (LT). HM: half-marathon; * represents that there was a significant difference at the same time point between PT and IG; t represents that there was a significant change from pre to post time points in PT; \# represents that there was a significant change from pre to post time points in IG. $p<0.05$ was considered to be a statistically significant difference within and between the groups.

\section{Discussion}

There was no significant difference between PT and LT in HM, indicating that taking PS128 for 4 weeks did not significantly improve the performance of HM. However, comparing the split time of HM, it was found that only PT in Stage 4 was significantly slower 
than LT. However, there was no significant difference between Stage 3 and Stage 4 in LT. This showed that LT had a lower level of fatigue compared to PT.

In order to explore the difference in HM between the two treatments, the exercise capacity was tested; after 4 weeks of nutritional supplements, there were no significant differences in lower limb muscle strength, anaerobic power, lower limb explosive power, or aerobic capacity. From the analysis of blood tests, there were no significant differences in indicators such as muscle fatigue, muscle damage, renal damage, and antioxidant indicators. It could be seen that only taking PS128 for 4 weeks did not significantly improve exercise capacity. This showed that the mechanism of better anti-fatigue ability in LT during HM was not due to the improvement in exercise performance. This could be attributed to less muscle damage suffered; for example, myoglobin, LDH, and CPK were significantly lower in LT after HM compared with PT, which improved participants' ability to maintain pace.

From the perspective of the recovery of exercise capacity after the HM intervention, it could be found that LT did not significantly decrease after the HM intervention, and it was significantly greater than $\mathrm{PT}$ at $3 \mathrm{~h}$ post, $24 \mathrm{~h}$ post, $48 \mathrm{~h}$ post, $72 \mathrm{~h}$ post, and $96 \mathrm{~h}$ post stages, indicating that it had better anti-fatigue ability or recovery. Long-distance running usually involves a large amount of quadriceps and eccentric contraction to absorb the impact of body weight when the heel comes into contact with the floor, causing muscle damage and leading to patella pain syndrome, iliotibial band syndrome, and patellar tendinitis. Such symptoms indirectly affect the maximum torque of the knee extensor muscles [39]. The 2004 study by Dowson et al. on eight male and four female recreational runners showed significant decreases in the knee extensor peak torque within $24 \mathrm{~h}$ after HM (return to baseline at $96 \mathrm{~h}$ post) and no significant change in knee flexor peak torque, which is consistent with the findings of this study [40]. Knee extensor peak torque is associated with the exercise capacity in the squat jump (SJ) and CMJ [41]. The study by Martínez-Sánchez et al. in 2017 on 21 male recreational runners showed significant decreases in both SJ and CMJ height and obvious muscle soreness up to $72 \mathrm{~h}$ after HM [42]. Similarly, in the study by Wiewelhove et al. in 2018, approximately 46 male recreational runners showed obvious decreases in CMJ height after HM [43]. The CMJ height in PT was significantly reduced after HM intervention and lasted for $24 \mathrm{~h}$, but LT did not change at all. In the absence of a significant improvement in exercise capacity indicators, the maximum muscle strength and explosive power in LT after the HM intervention did not significantly decrease. This result highlights the need for further investigation of the mechanism of influence from changes in blood indicators.

Reduced muscle damage and faster recovery may lead to an enhanced adaptation rate to training and, subsequently, to a faster increase in hypertrophy and performance. Exercise-induced skeletal muscle tissue damage occurs as a result of the forced lengthening of an active muscle, which directly causes microtears of the myofibrils, resulting in muscle soreness and swelling, and decreased forced production. The initial reaction is followed by a secondary inflammatory response integral to skeletal muscle repair and recovery response. While muscle damage appears to be an important component of muscular adaptation to exercise, a reduction in and not a complete prevention of muscle damage, as shown by the addition of B. coagulans GBI-30 and 6086 to casein, might be optimal [22]. In blood analysis, muscle fatigue indices (e.g., $\mathrm{BCAA}$ and $\mathrm{NH}_{3}$ ) showed no significant difference in recovery after HM between the two treatments, whereas muscle damage indices (e.g., myoglobin and CPK) after HM in LT were significantly lower than those in PT, indicating the positive effect of the nutritional supplement on muscle damage. This is consistent with the findings of the study by Huang et al. [32], where the negative impact of high-intensity sports on exercise capacity was reduced by improving anti-inflammatory, antioxidation, and metabolic functions. High-intensity exercise may result in muscle damage, an imbalance of calcium homeostasis, the infiltration of neutrophils, and the production of free radicals and cytohormone metabolites, thereby resulting in elevated inflammatory (e.g., CPK and LDH) and oxidative stress-related (e.g., SOD and CAT) biomarkers [44]. DOMS is primarily caused by exercise-induced muscle damage (EIMD), frequently after unaccustomed or 
damaging exercise (e.g., downhill running). Leucocyte infiltration in injured tissues may cause muscular fiber damage and secondary inflammation [10,45], combined with the associated symptoms persisting for several days after exercise, such as muscle soreness; a reduced pain threshold; local swelling; a transient decrease in maximal power; and elevated levels of myoglobin, LDH, and CPK [46,47]. Similarly, in this study, muscle damage indices (i.e., myoglobin, $\mathrm{LDH}$, and $\mathrm{CPK}$ ) showed a significant increase, suggesting DOMS; lower extremity maximal muscle strength showed a significant decrease after HM in both PT and LT, as demonstrated in the study by Boccia et al. in 2017 [48]. No gender difference was observed in the study by Boccia et al. in 2018 [49]. However, after PS128 intervention, muscle damage indices were improved, the antioxidation indicator SOD elevated significantly, and exercise capacity was superior to that in PT, which seems to be the mechanism of action for PS128 to improve exercise capacity after HM, such as lower extremity muscle strength and lower extremity explosive force. PS128 has a similar mechanism to other nutritional supplements (i.e., fruit extracts, plant extracts, herb extracts, amino acids, and proteins) [50] in reducing EIMD, where muscle damage, DOMS, and inflammation are reduced and muscle function is improved via antioxidative and anti-inflammatory mechanisms. In terms of renal injury, BUN elevated significantly after HM in both LT and PT, as demonstrated by McCullough et al. [51]. It returned to baseline at $24 \mathrm{~h}$ post-LT, indicating better recovery. The mechanism that affects the changes in blood indicators needs to be explored based on the regulation mechanism of PS128 in the immune system.

PS128 reduced the production of lipopolysaccharide-induced proinflammatory cytokines in a RAW 264.7 mouse macrophage model and had positive regulatory effects on inflammation, oxidation, and metabolism caused by high-intensity exercise [32], as evidenced in this study, in which PS128 had significant regulatory effects on myoglobin, LDH, $\mathrm{CPK}$, and SOD. In both clinical and nonclinical studies, L. plantarum has been demonstrated to exert anti-inflammatory activity and a regulatory effect on the immune response in hosts. Teichoic acids (TAs) produced by L. plantarum are the crucial substances that regulate the systematic immune response in mice [30]. By gene sequence alignment, it was found that L. plantarum PS128, WCFS1, and B21 have the core genes responsible for the metabolism, translation, and modification of TAs [30].

Despite the promising results, this study had several limitations. Although it used a repeated-measures design to include more participants (PT, $n=8$; LT, $n=8$ ), the low number of participants makes the results highly unreliable due to the low representation. The original aim was for 16 participants to complete the study. Recruitment was hindered by an unexpectedly high percentage of recreational runners who could not accommodate the experiment time of this study. As it was not possible to run on the road like in an actual competition, the test could only be carried out on a $400 \mathrm{~m}$ track in a field stadium, but the environmental factors were well controlled. The strengths of this study were that there were large number of sampling time points during the experimental period to investigate the exact reaction of related biochemical indicators with conditions of physiological limitation. This could obtain more information about the situation of recovery after HM. The detailed mechanisms affected by probiotics should be further investigated via systemic biological tools, such as proteomics and metabolomics, in the future.

\section{Conclusions}

In conclusion, PS128 supplementation was associated with an improvement in muscle damage, renal damage and oxidative stress caused by HM through microbiota modulation and related metabolites, but not in exercise capacity, thus neutralizing the ROS caused by exhaustive and prolonged exercise. Probiotics may represent an effective supplementation for athletes to establish an appropriate antioxidant barrier for preventing dangerous levels of oxidative stress. They could also shorten the return to play due to the consumption of PS128 instead of NSAIDs.

Author Contributions: K.-W.T. designed the experiments. W.-C.T. and C.-C.L. carried out the laboratory experiments. Y.-C.T. contributed reagents, materials, and analysis platforms. H.-L.T. 
analyzed the data. S.-K.F. and C.-C.H. interpreted the results, prepared the figures, wrote the manuscript, and revised the manuscript. All authors have read and agreed to the published version of the manuscript.

Funding: This research received no external funding.

Institutional Review Board Statement: The study was conducted according to the guidelines of the Declaration of Helsinki, and approved by the Institutional Review Board of University of Taipei (protocol code IRB-2020-054 and date of approval 18 September 2020).

Informed Consent Statement: Informed consent was obtained from all subjects involved in the study.

Data Availability Statement: The data presented in this study are available on request from the corresponding author. The data are not publicly available due to privacy.

Acknowledgments: The authors are grateful to the University of Taipei, National Yang-Ming ChiaoTung University, and Taipei City Hospital for their technical assistance in conducting the experiments.

Conflicts of Interest: The authors declare no conflict of interest.

\section{References}

1. Clifford, T.; Allerton, D.M.; Brown, M.A.; Harper, L.; Horsburgh, S.; Keane, K.M.; Stevenson, E.J.; Howatson, G. Minimal muscle damage after a marathon and no influence of beetroot juice on inflammation and recovery. Appl. Physiol. Nutr. Metab. 2017, 42, 263-270. [CrossRef]

2. Takayama, F.; Aoyagi, A.; Shimazu, W.; Nabekura, Y. Effects of Marathon Running on Aerobic Fitness and Performance in Recreational Runners One Week after a Race. J Sports Med (Hindawi Publ Corp). 2017, 2017, 9402386. [CrossRef] [PubMed]

3. Junker, D.; Stöggl, T. The Training Effects of Foam Rolling on Core Strength Endurance, Balance, Muscle Performance and Range of Motion: A Randomized Controlled Trial. Sports Sci. Med. 2019, 18, 229-238.

4. Brentano, M.A.; Martins Kruel, L.F. A review on strength exercise-induced muscle damage: Applications, adaptation mechanisms and limitations. J. Sports Med. Phys. Fitness 2011, 51, 1-10. [PubMed]

5. Rubio-Arias, J.Á.; Ávila-Gandía, V.; López-Román, F.J.; Soto-Méndez, F.; Alcaraz, P.E.; Ramos-Campo, D.J. Muscle damage and inflammation biomarkers after two ultra-endurance mountain races of different distances: $54 \mathrm{~km}$ vs $111 \mathrm{~km}$. Physiol. Behav. 2019, 205, 51-57. [CrossRef]

6. Lynn, A.; Garner, S.; Nelson, N.; Simper, T.N.; Hall, A.C.; Ranchordas, M.K. Effect of bilberry juice on indices of muscle damage and inflammation in runners completing a half-marathon: A randomised, placebo-controlled trial. J. Int. Soc. Sports Nutr. 2018, 15, 22. [CrossRef] [PubMed]

7. Hooijmans, M.T.; Monte, J.R.C.; Froeling, M.; van den Berg-Faay, S.; Aengevaeren, V.L.; Hemke, R.; Smithuis, F.F.; Eijsvogels, T.M.H.; Bakermans, A.J.; Maas, M.; et al. Quantitative MRI Reveals Microstructural Changes in the Upper Leg Muscles After Running a Marathon. J. Magn. Reson. Imaging 2020, 52, 407-417. [CrossRef]

8. Wan, B.; Shan, G. Biomechanical modeling as a practical tool for predicting injury risk related to repetitive muscle lengthening during learning and training of human complex motor skills. SpringerPlus 2016, 5, 441. [CrossRef] [PubMed]

9. Gorski, T.; Cadore, E.L.; Pinto, S.S.; da Silva, E.M.; Correa, C.S.; Beltrami, F.G.; Kruel, L.F.M. Use of NSAIDs in triathletes: Prevalence, level of awareness and reasons for use. Br. J. Sports Med. 2011, 45, 85. [CrossRef] [PubMed]

10. Howatson, G.; van Someren, K.A. The Prevention and Treatment of Exercise-Induced Muscle Damage. Sports Med. 2008, 38, 483-503. [CrossRef] [PubMed]

11. Hill, C.; Guarner, F.; Reid, G.; Gibson, G.R.; Merenstein, D.J.; Pot, B.; Morelli, L.; Canani, R.B.; Flint, H.J.; Salminen, S.; et al. The International Scientific Association for Probiotics and Prebiotics consensus statement on the scope and appropriate use of the term probiotic. Nat. Rev. Gastroenterol. Hepatol. 2014, 11, 506. [CrossRef] [PubMed]

12. Fijan, S. Microorganisms with claimed probiotic properties: An overview of recent literature. Int. J. Environ. Res. Public Health 2014, 11, 4745-4767. [CrossRef] [PubMed]

13. Vaghef-Mehrabany, E.; Alipour, B.; Homayouni-Rad, A.; Sharif, S.-K.; Asghari-Jafarabadi, M.; Zavvari, S. Probiotic supplementation improves inflammatory status in patients with rheumatoid arthritis. Nutrition 2014, 30, 430-435. [CrossRef] [PubMed]

14. Phavichitr, N.; Puwdee, P.; Tantibhaedhyangkul, R. Cost-benefit analysis of the probiotic treatment of children hospitalized for acute diarrhea in Bangkok, Thailand. Southeast. Asian J. Trop. Med. Public Health 2013, 44, 1065-1071.

15. Ciccarelli, S.; Stolfi, I.; Caramia, G. Management strategies in the treatment of neonatal and pediatric gastroenteritis. Infect. Drug Resist. 2013, 6, 133-161.

16. Pyne, D.; West, N.; Cox, A.; Cripps, A. Probiotics supplementation for athletes-Clinical and physiological effects. Eur. J. Sport Sci. 2014, 15, 1-10. [CrossRef] [PubMed]

17. Jäger, R.; Purpura, M.; Stone, J.; Turner, S.; Anzalone, A.; Eimerbrink, M.; Pane, M.; Amoruso, A.; Rowlands, D.; Oliver, J. Probiotic Streptococcus thermophilus FP4 and Bifidobacterium breve BR03 Supplementation Attenuates Performance and Range-of-Motion Decrements Following Muscle Damaging Exercise. Nutrients 2016, 8, 642. [CrossRef] [PubMed] 
18. Huang, W.-C.; Hsu, Y.-J.; Li, H.; Kan, N.-W.; Chen, Y.-M.; Lin, J.-S.; Hsu, T.-K.; Tsai, T.-Y.; Chiu, Y.-S.; Huang, C.-C. Effect of Lactobacillus Plantarum TWK10 on Improving Endurance Performance in Humans. Chin. J. Physiol. 2018, 61, 163-170. [CrossRef] [PubMed]

19. Chen, Y.-M.; Wei, L.; Chiu, Y.-S.; Hsu, Y.-J.; Tsai, T.-Y.; Wang, M.-F.; Huang, C.-C. Lactobacillus plantarum TWK10 Supplementation Improves Exercise Performance and Increases Muscle Mass in Mice. Nutrients 2016, 8, 205. [CrossRef] [PubMed]

20. Komano, Y.; Shimada, K.; Naito, H.; Fukao, K.; Ishihara, Y.; Fujii, T.; Kokubo, T.; Daida, H. Efficacy of heat-killed Lactococcus lactis JCM 5805 on immunity and fatigue during consecutive high intensity exercise in male athletes: A randomized, placebo-controlled, double-blinded trial. J. Int. Soc. Sports Nutr. 2018, 15, 39. [CrossRef]

21. Martarelli, D.; Verdenelli, M.C.; Scuri, S.; Cocchioni, M.; Silvi, S.; Cecchini, C.; Pompei, P. Effect of a Probiotic Intake on Oxidant and Antioxidant Parameters in Plasma of Athletes During Intense Exercise Training. Curr. Microbiol. 2011, 62, 1689-1696. [CrossRef] [PubMed]

22. Jäger, R.; Purpura, M.; Farmer, S.; Cash, H.A.; Keller, D. Probiotic Bacillus coagulans GBI-30, 6086 Improves Protein Absorption and Utilization. Probiotics Antimicrob. Proteins 2018, 10, 611-615. [CrossRef] [PubMed]

23. Alkema, W.; Boekhorst, J.; Wels, M.; van Hijum, S.A.F.T. Microbial bioinformatics for food safety and production. Brief. Bioinform. 2016, 17, 283-292. [CrossRef] [PubMed]

24. Hsieh, M.-C.; Tsai, W.-H.; Jheng, Y.-P.; Su, S.-L.; Wang, S.-Y.; Lin, C.-C.; Chen, Y.-H.; Chang, W.-W. The beneficial effects of Lactobacillus reuteri ADR-1 or ADR-3 consumption on type 2 diabetes mellitus: A randomized, double-blinded, placebocontrolled trial. Sci. Rep. 2018, 8, 1-11. [CrossRef] [PubMed]

25. Toral, M.; Romero, M.; Rodríguez-Nogales, A.; Jiménez, R.; Robles-Vera, I.; Algieri, F.; Chueca-Porcuna, N.; Sánchez, M.; de la Visitación, N.; Olivares, M.; et al. Lactobacillus fermentum Improves Tacrolimus-Induced Hypertension by Restoring Vascular Redox State and Improving eNOS Coupling. Mol. Nutr. Food Res. 2018, 62, 1800033. [CrossRef]

26. Oh, N.S.; Joung, J.Y.; Lee, J.Y.; Kim, Y. Probiotic and anti-inflammatory potential of Lactobacillus rhamnosus 4 B15 and Lactobacillus gasseri 4M13 isolated from infant feces. PLoS ONE 2018, 13, e0192021. [CrossRef] [PubMed]

27. Son, S.H.; Yang, S.J.; Jeon, H.L.; Yu, H.S.; Lee, N.K.; Park, Y.S.; Paik, H.D. Antioxidant and immunostimulatory effect of potential probiotic Lactobacillus paraplantarum SC61 isolated from Korean traditional fermented food, jangajji. Microb. Pathog. 2018, 125, 486-492. [CrossRef]

28. Chao, S.H.; Wu, R.J.; Watanabe, K.; Tsai, Y.C. Diversity of lactic acid bacteria in suan-tsai and fu-tsai, traditional fermented mustard products of Taiwan. Int. J. Food Microbiol. 2009, 135, 203-210. [CrossRef] [PubMed]

29. Liu, Y.-W.; Liong, M.T.; Chung, Y.-C.E.; Huang, H.-Y.; Peng, W.-S.; Cheng, Y.-F.; Lin, Y.-S.; Wu, Y.-Y.; Tsai, Y.-C. Effects of Lactobacillus plantarum PS128 on Children with Autism Spectrum Disorder in Taiwan: A Randomized, Double-Blind, PlaceboControlled Trial. Nutrients 2019, 11, 820. [CrossRef] [PubMed]

30. Liu, W.-H.; Yang, C.-H.; Lin, C.-T.; Li, S.-W.; Cheng, W.-S.; Jiang, Y.-P.; Wu, C.-C.; Chang, C.-H.; Tsai, Y.-C. Genome architecture of Lactobacillus plantarum PS128, a probiotic strain with potential immunomodulatory activity. Gut Pathog. 2015, 7, 22. [CrossRef] [PubMed]

31. Liu, W.-H.; Chuang, H.-L.; Huang, Y.-T.; Wu, C.-C.; Chou, G.-T.; Wang, S.; Tsai, Y.-C. Alteration of behavior and monoamine levels attributable to Lactobacillus plantarum PS128 in germ-free mice. Behav. Brain Res. 2016, 298, 202-209. [CrossRef]

32. Huang, W.-C.; Wei, C.-C.; Huang, C.-C.; Chen, W.-L.; Huang, H.-Y. The Beneficial Effects of Lactobacillus plantarum PS128 on High-Intensity, Exercise-Induced Oxidative Stress, Inflammation, and Performance in Triathletes. Nutrients 2019, 11, 353. [CrossRef]

33. Huang, W.-C.; Pan, C.-H.; Wei, C.-C.; Huang, H.-Y. Lactobacillus plantarum PS128 Improves Physiological Adaptation and Performance in Triathletes through Gut Microbiota Modulation. Nutrients 2020, 12, 2315. [CrossRef] [PubMed]

34. Chen, T.C.; Chen, H.L.; Lin, M.J.; Wu, C.J.; Nosaka, K. Muscle damage responses of the elbow flexors to four maximal eccentric exercise bouts performed every 4 weeks. Eur. J. Appl. Physiol. 2009, 106, 267-275. [CrossRef]

35. Bar-Or, O. The Wingate anaerobic test. An update on methodology, reliability and validity. Sports Med. 1987, 4, 381-394. [CrossRef] [PubMed]

36. Moir, G.L. Three Different Methods of Calculating Vertical Jump Height from Force Platform Data in Men and Women. Meas. Phys. Educ. Exerc. Sci. 2008, 12, 207-218. [CrossRef]

37. Nieman, D.C.; Austin, M.D.; Dew, D.; Utter, A.C. Validity of COSMED's quark CPET mixing chamber system in evaluating energy metabolism during aerobic exercise in healthy male adults. Res. Sports Med. 2013, 21, 136-145. [CrossRef]

38. Hall-Lopez, J.A.; Ochoa-Martinez, P.Y.; Moncada-Jimenez, J.; Ocampo Mendez, M.A.; Martinez Garcia, I.; Martinez Garcia, M.A. Reliability of the maximal oxygen uptake following two consecutive trials by indirect calorimetry. Nutr. Hosp. 2015, 31, 1726-1732. [PubMed]

39. Mullaney, M.J.; Fukunaga, T. Current concepts and treatment of patellofemoral compressive issues. Int. J. Sports Phys. Ther. 2016, $11,891-902$.

40. Dawson, L.G.; Dawson, K.A.; Tiidus, P.M. Evaluating the influence of massage on leg strength, swelling, and pain following a half-marathon. J. Sports Sci. Med. 2004, 3, 37-43. [PubMed]

41. Suzuki, K.; Peake, J.; Nosaka, K.; Okutsu, M.; Abbiss, C.R.; Surriano, R.; Bishop, D.; Quod, M.J.; Lee, H.; Martin, D.T.; et al. Changes in markers of muscle damage, inflammation and HSP70 after an Ironman Triathlon race. Eur. J. Appl. Physiol. 2006, 98, 525-534. [CrossRef] [PubMed] 
42. Martínez-Sánchez, A.; Ramos-Campo, D.J.; Fernández-Lobato, B.; Rubio-Arias, J.A.; Alacid, F.; Aguayo, E. Biochemical, physiological, and performance response of a functional watermelon juice enriched in L-citrulline during a half-marathon race. Food Nutr. Res. 2017, 61, 1330098. [CrossRef] [PubMed]

43. Wiewelhove, T.; Schneider, C.; Döweling, A.; Hanakam, F.; Rasche, C.; Meyer, T.; Kellmann, M.; Pfeiffer, M.; Ferrauti, A. Effects of different recovery strategies following a half-marathon on fatigue markers in recreational runners. PLoS ONE 2018, 13, e0207313. [CrossRef]

44. Withee, E.D.; Tippens, K.M.; Dehen, R.; Tibbitts, D.; Hanes, D.; Zwickey, H. Effects of Methylsulfonylmethane (MSM) on exerciseinduced oxidative stress, muscle damage, and pain following a half-marathon: A double-blind, randomized, placebo-controlled trial. J. Int. Soc. Sports Nutr. 2017, 14, 24. [CrossRef]

45. Clarkson, P.M.; Sayers, S.P. Etiology of exercise-induced muscle damage. J. Appl. Physiol. 1999, 24, 234-248. [CrossRef]

46. Clarkson, P.M.; Hubal, M.J. Exercise-induced muscle damage in humans. Am. J. Phys. Med. Rehabil. 2002, 81, S52-S69. [CrossRef] [PubMed]

47. Byrne, C.; Eston, R.G.; Edwards, R.H. Characteristics of isometric and dynamic strength loss following eccentric exercise-induced muscle damage. Scand J. Med. Sci. Sports 2001, 11, 134-140. [CrossRef]

48. Boccia, G.; Dardanello, D.; Tarperi, C.; Rosso, V.; Festa, L.; La Torre, A.; Pellegrini, B.; Schena, F.; Rainoldi, A. Decrease of muscle fiber conduction velocity correlates with strength loss after an endurance run. Physiol. Meas. 2017, 38, 233-240. [CrossRef] [PubMed]

49. Boccia, G.; Dardanello, D.; Tarperi, C.; Festa, L.; La Torre, A.; Pellegrini, B.; Schena, F.; Rainoldi, A. Women show similar central and peripheral fatigue to men after half-marathon. J. Sport Sci. 2018, 18, 695-704. [CrossRef] [PubMed]

50. Harty, P.S.; Cottet, M.L.; Malloy, J.K.; Kerksick, C.M. Nutritional and Supplementation Strategies to Prevent and Attenuate Exercise-Induced Muscle Damage: A Brief Review. Sports Med. Open 2019, 5, 1. [CrossRef]

51. McCullough, P.A.; Chinnaiyan, K.M.; Gallagher, M.J.; Colar, J.M.; Geddes, T.; Gold, J.M.; Trivax, J.E. Changes in renal markers and acute kidney injury after marathon running. Nephrology 2011, 16, 194-199. [CrossRef] 